\title{
Crotalus durissus terrificus Venom Interferes With Morphological, Functional, and Biochemical Changes in Murine Macrophage
}

\author{
Anselmo Hernández Cruz, ${ }^{1}$ Ronaldo Z. Mendonça, ${ }^{2}$ and Vera L. Petricevich ${ }^{1}$ \\ ${ }^{1}$ Facultad de Medicina, Universidad Autónoma del Estado de Morelos, \\ Avenida Universidad 1001, Cuernavaca, Morelos 62210, Mexico \\ ${ }^{2}$ Laboratorio de Imunologia Viral, Instituto Butantan, 05503-900 São Paulo, Brazil
}

Received 4 July 2005; accepted 1 September 2005

\begin{abstract}
Crotalus durissus terrificus venom (Cdt) is toxic for a variety of eukaryotic cells, especially at high concentrations. However its effects on host immune cells are not well known. The purpose of this study was to determine the effect of Cdt on functional status and the mediators production in peritoneal macrophages. The effects of Cdt were analyzed in vitro and were detected using functional status of macrophages as determined by the $\mathrm{H}_{2} \mathrm{O}_{2}$ release, spreading percentage, phagocytic index, vacuole formation, and mediators production. Several functional bioassays were employed: cytotoxicity was determined by taking the lyses percentage and the presence of hydrogen peroxide $\left(\mathrm{H}_{2} \mathrm{O}_{2}\right)$ in macrophages, using the horseradish peroxidase-dependent oxidation of phenol red and nitric oxide (NO) in the supernatants of macrophages by the Griess reaction. The tumor necrosis factor (TNF) activity was detected by measuring its cytotoxic activity on L929 cells, and the production the level of other cytokines was assayed using enzyme-linked immunosorbent assay. In vitro studies revealed that Cdt produced (a) a discrete increase in the release of $\mathrm{H}_{2} \mathrm{O}_{2}$ and vacuole formation; (b) a decrease in spreading percentage and in the phagocytic index; and (c) an increment in the mediators production. More pronounced increments of IL-6 and TNF were observed after 24 and 48 hours, respectively. Maximum levels of IFN- $\gamma$ and NO were observed after 96 hours. Interestingly, levels of all mediators presented a discreet decrease, as the amount of Cdt was increased. In contrast, the IL-10 levels observed for all doses studied here did not alter. The IL-6/IL-10 ratio may possibly reflect the balance of pro- and anti-inflammatory cytokines in macrophages, which may be manifested in the inflammatory status during the envenoming processes. Taken together, these data indicate that Cdt have a differential effect on macrophage activation and that this venom is a potent inhibitor of anti-inflammatory response.
\end{abstract}

\section{INTRODUCTION}

Snakes venom varies enormously, in terms of their biological properties, chemical composition, toxicity, biological actions, and pharmacokinetics, and pharmacodynamic characteristics. Crotalus venom is considered to be one of the most dangerous species for humans. This snake is found in different parts of world, and is responsible for many clinical cases of envenoming. Its venom contains a variety of toxic proteins including crotoxin, crotamine, gyroxin, convulsin, and a thrombin-like enzyme $[1,2]$. It also induces toxic activity causing neurotoxicity, respiratory paralysis, hypotension, acute renal insufficiency, myotoxicity, hepatotoxicity and hemorrhagic alterations, and shock $[3,4,5]$.

Correspondence and reprint requests to Vera L. Petricevich, Facultad de Medicina, Universidad Autónoma del Estado de Morelos, Avenida Universidad 1001, Cuernavaca, Morelos 62210, Mexico; vera.petricevich@uaem.mx
It is well known that the lethality and toxicity of snake venoms can vary according to their age, sex, and nutritional state depending on the geographic region where the animals were captured [6]. Thus, aiming to minimize the experimental bias of this investigation, all tests were carried out on BALB/c mice using a mixture of Crotalus durissus terrificus venom (Cdt) which was obtained from 50 adult specimens, captured in the same geographic region for all experiments.

Experimental studies have shown that certain venoms may bring on systemic inflammatory response syndrome $[7,8,9,10]$.

The positive outcome of the inflammatory response helps eliminate the chemical, physical, or infectious factors which originally provoked the inflammation, and it also repairs damage and/or regenerates the injured tissue. The activated macrophages are widely recognized as cells which play an important role in the inflammatory process, as well as in the initiation, maintenance, and control of specific immune response. In response to venoms, macrophages secrete the so-called nitric oxide 
(NO) and proinflammatory cytokines such as tumor necrosis factor (TNF), interleukin-1 (IL-1), and IL-6 and anti-inflammatory cytokines, for example, IL-10 [11].

The production of pro- and anti-inflammatory cytokines is strictly controlled by complex feedback mechanisms $[12,13]$. Proinflammatory cytokines are primarily responsible for initiating an effect against exogenous pathogens. However, excessive production of these mediators may significantly contribute to shock, multiple organ failure, and death $[11,14,15,16,17]$. In contrast, anti-inflammatory cytokines are crucial for down regulating the incremented inflammatory process and maintaining homeostasis for the correct functioning of vital organs $[18,19]$.

Although the pathophysiology of envenomation is complex and not yet fully understood, venom and immune responses are known to trigger the release of cytokines. In models of severe systemic inflammation produced by intravenous injection of high doses of venom or venoms products, the increase in production of proinflammatory cytokines significantly contributes to organ failure and death. These cytokines initiate a cascade of events that lead to illness behaviors such as fever, anorexia, and also physiological events in the host such as activation of vasodilatation, hypotension, and increased vessel permeability.

In 1997, Cardoso and Mota [20] demonstrated that the venom of $C$ durissus terrificus inhibits the humoral immune response in mice. Other studies have shown that the macrophage may play a role in regulating the immune response to this venom $[21,22]$. Since then, the macrophage is integral to the induction of immunity to this venom, it is presumed that the final outcome of many inhibitory events may be alterations in macrophage function $[21,22]$. However a detailed description of the events provoked by this venom, which inhibit macrophage activation is still unclear.

This study was designed to determine the effect of Cdt on functional status and mediators production. The levels of macrophage activation induced by Cdt were related to the magnitude of the inflammatory response.

\section{MATERIALS AND METHODS}

\section{Chemicals, reagents, and buffers}

Actinomycin D, orthophenyldiamine (OPD) and sodium nitrate (NO), fetal calf serum (FCS), RPMI-1640 medium were purchased from Sigma (St. Louis, Mo), murine anti-IL-6 (clones MP5-20F3 and MP5-32C11), recombinant IL-6, murine anti-IFN- $\gamma$ (clones XGM1.2 and R4-6A2), recombinant IFN- $\gamma$, murine anti-IL-10 (clones JES5-16E3 and SXC-1), recombinant IL-10, were purchased from BD Biosciences Pharmingen, and recombinant TNF was purchased from Boehring Mannheim (Mannheim, Germany).

\section{Venom}

Lyophilized venom of $C$ durissus terrificus was obtained from the Laboratory of Herpetology, Instituto $\mathrm{Bu}$ tantan, São Paulo, Brazil, and stored at $-20^{\circ} \mathrm{C}$. The venom was dissolved in sterile physiological saline $[0.85 \%(\mathrm{w} / \mathrm{v})$ $\mathrm{NaCl}$ solution].

\section{Animals}

Female BALB/c mice (6-8 weeks old, weighing $18 \mathrm{~g}-$ $25 \mathrm{~g}$ ) were purchased from Instituto de Biotecnología, UNAM (Cuernavaca, Mexico). The animals were maintained and used under strict ethical conditions according to international recommendations for animal welfare set by Committee Members, International Society on Toxicology [23].

\section{Peritoneal macrophages}

Groups of mice from BALB/c were sacrificed and their resident peritoneal cells were harvested by peritoneal lavage [24]. The peritoneal cavity was injected with $5 \mathrm{~mL}$ of cold RPMI-1640. The fluid-distended peritoneal cavity was massaged, and the cells were collected and washed three times by centrifugation at $290 \mathrm{xg}$ for 5 minutes. The cells were seeded in 96-well microtiter plates at a concentration of $1 \times 10^{6}$ cells $/ \mathrm{mL}$, and cultured in RPMI-1640 medium supplemented with $10 \%$ FCS. Cell viability ranged from $90 \%-97 \%$ and was determined by Trypan blue exclusion. After incubation at $37^{\circ} \mathrm{C}$ for 2 hours in humidified $5 \% \mathrm{CO}_{2}$, the plates were then washed twice with RPMI-1640 medium to remove nonadherent cells and the adherent cells were referred to as macrophages. More than $95 \%$ of the cells were identified as macrophages by morphology as well as by their ability to ingest IgG-opsonised red cells. The cells were exposed to different concentrations of Cdt in RPMI-1640 containing $10 \% \mathrm{FCS}$. After incubation at $37^{\circ} \mathrm{C}$ for various intervals of time in a humidified atmosphere of $5 \% \mathrm{CO}_{2}$, the supernatants were collected and stored at $-20^{\circ} \mathrm{C}$ until assayed for the presence of $\mathrm{NO}$ and $\mathrm{cy}$ tokines.

\section{Cytotoxicity assay}

In brief, macrophage cells maintained in RPMI-1640 medium supplemented with $10 \%$ FCS were seeded at $1 \times 10^{6} \mathrm{cells} / \mathrm{mL}$ on to a 96-well plate, control and/or treated cells with different amounts of venom were incubated at $37^{\circ} \mathrm{C}$ in a $5 \% \mathrm{CO}_{2}$ atmosphere. After different times of incubation, the supernatants were removed and the remaining live cells assessed by fixing and staining with crystal violet ( $0.2 \%$ in $20 \%$ methanol). Absorbance was measured in each well by reading at $620 \mathrm{~nm}$ in a microplate reader. The percentage cytotoxicity was calculated as follows: $\left(A_{\text {control }}-A_{\text {sample }} / A_{\text {control }}\right) \times$ 100. 


\section{FUNCTIONAL STATUS ASSAYS}

\section{Hydrogen peroxide}

$\mathrm{H}_{2} \mathrm{O}_{2}$ was measured by the horseradish peroxidasedependent oxidation of phenol red [25]. Peritoneal macrophages were obtained as described previously, exposed at different doses of venom, and incubated for determined times at $37^{\circ} \mathrm{C}$ with $5 \% \mathrm{CO}_{2}$. The media were aspirated and the red phenol solution containing $140 \mathrm{mM} \mathrm{NaCl} ; 10 \mathrm{mM} \mathrm{K}_{2} \mathrm{PO}_{4} ; 5.5 \mathrm{mM}$ dextrose; and $5.5 \mathrm{mM}$ horseradish peroxidase was added to the adherent cells. After 1 hour incubation at $37^{\circ} \mathrm{C} 10 \mu \mathrm{L}$ of $1 \mathrm{~N}$ $\mathrm{NaOH}$ were added per well. The absorbance was measured at $620 \mathrm{~nm}$, using automatic enzyme immunoassay reader the levels of $\mathrm{H}_{2} \mathrm{O}_{2}$ was quantitated by comparison with standard curve prepared with known concentrations of $\mathrm{H}_{2} \mathrm{O}_{2}$.

\section{Phagocytosis assays}

Binding and phagocytosis of yeast were analyzed in vitro as described by Zebedee et al [26]. Briefly, $1 \times$ $10^{6}$ cells $/ \mathrm{mL}$ were seeded in triplicate on 24 -well tissue culture plates, containing slides and cultured in RPMI1640 plus $10 \%$ FCS. After incubating at $37^{\circ} \mathrm{C}$ for 2 hours in humidified $5 \% \mathrm{CO}_{2}$, cells slides were rinsed in normal saline to remove nonadherent cells. The adherent cells were exposed to different amounts of Cdt and/or saline solution. After various intervals opsonized yeasts, at an effector-to-target ratio of 1:5, were added to macrophage cultures for varying periods at $37^{\circ} \mathrm{C}$. Unattached yeasts were removed by washing wells three times with PBS. The media were aspirated, and the cells were fixed with methanol for 20 minutes at room temperature and washed three times with PBS and stained with safranine for 40 seconds. The fixed slides were mounted with coverslips and were then examined using a microscope at $40 \times$ magnification. Three coverslips per experimental condition were used to determine the percentage of phagocytic cells. The phagocytic index (PI) was calculated as follows: number of macrophages with internalized yeast/100.

\section{Spreading}

The macrophage spreading assays were performed as previously described by Arruda et al [27]. Briefly, $1 \times$ $10^{6}$ cells $/ \mathrm{mL}$ were seeded in triplicate, on 24 -well plates containing slides to assess cell adhesion and cultured in RPMI-1640 plus $10 \%$ FCS. After incubation at $37^{\circ} \mathrm{C}$ for 2 hours in humidified $5 \% \mathrm{CO}_{2}$, cells slides were rinsed in normal saline to remove nonadherent cells. The adherent cells were exposed to different amounts of Cdt and/or saline solution. After different time periods, the cells were fixed with methanol and then stained with crystal violet for 1 minute. Slides were mounted with coverslips and examined by light microscopy at $40 \times$ magnification. Spread cells from three different areas of each of the triplicate wells were counted after being incubated with Cdt.
The spreading index (SI) equals a percentage value of 100 macrophages.

\section{Vacuolation assay}

Peritoneal macrophages were obtained and maintained as described above. For the vacuolation assay the macrophages were incubated with the RPMI-1640 medium supplemented with $5 \%$ FCS and $1 \mathrm{mM} / \mathrm{mL}$ $\mathrm{NH}_{4} \mathrm{Cl}^{28}$ and exposed to different amounts of Cdt. The plates were incubated for different time periods at $37^{\circ} \mathrm{C}$ with $5 \% \mathrm{CO}_{2}$. To detect the vacuoles, cells cultures were stained with $0.05 \%$ neutral red solution for 5 minutes. The cells were washed with PBS containing $0.2 \%$ BSA, $70 \%$ ethanol, and $0.37 \% \mathrm{HCl}$. Absorbance was determined using microtiter reader plate at $540 \mathrm{~nm}$. Vacuolating percentage was calculated as follows: $\left(A_{\text {sample }}-\right.$ $\left.A_{\text {control }} / A_{\text {control }}\right) \times 100$.

\section{MEDIATORS PRODUCTION}

\section{Nitric oxide}

The levels of NO in supernatants from macrophages control or exposed to Cdt were assayed by adding $100 \mu \mathrm{L}$ of freshly prepared Griess reagent [28] to $100 \mu \mathrm{L}$ of the sample in 96-well plates, and then reading the absorbance at $540 \mathrm{~nm}, 10$ minutes later by comparison with the absorbance curves of serial dilutions of sodium nitrate in complete culture medium. The minimum level of NO detectable under the assay conditions was $1 \mathrm{nmol}$.

\section{Cytokines}

The levels of cytokines IL-6, IL-10, and IFN- $\gamma$ in the culture supernatants were assayed by a two-site sandwich enzyme-like immunosorbent assay (ELISA) [29]. In brief, ELISA plates were coated with $100 \mu \mathrm{L}(1 \mu \mathrm{g} / \mathrm{mL})$ of the monoclonal antibodies anti-IL-6, anti-IL-10, or antiIFN- $\gamma$ in $0.1 \mathrm{M}$ sodium carbonate buffer ( $\mathrm{pH} 8.2$ ) and incubated for 6 hours at room temperature. The wells were then washed with $0.1 \%$ phosphate-buffered saline (PBS/Tween-20) and blocked with $100 \mu \mathrm{L}$ of $10 \%$ FCS in PBS for 2 hours at room temperature. After washing, duplicate supernatant macrophage culture samples of $50 \mu \mathrm{L}$ were added to each well. After 18 hours of incubation at $4^{\circ} \mathrm{C}$, the wells were washed and incubated with $100 \mu \mathrm{L}$ $(2 \mu \mathrm{g} / \mathrm{mL})$ of the biotinylated monoclonal antibodies antiIL-6, anti-IL-10, or anti-IFN- $\gamma$ as second antibodies for 45 minutes at room temperature. After a final wash, the reaction was developed by the addition of OPD to each well. Optical densities were measured at $405 \mathrm{~nm}$ in a microplate reader. The cytokine content of each sample was read from a standard curve established with the appropriate recombinant cytokines (expressed in nanograms per milliliter). The minimum levels of each cytokine detectable in the conditions of the assays were $0.01,0.78$, and $0.3 \mathrm{ng} / \mathrm{mL}$ for IL-10, IL-6, and IFN- $\gamma$, respectively.

To measure the cytotoxicity of TNF present in the supernatants taken from the macrophages, a standard assay 


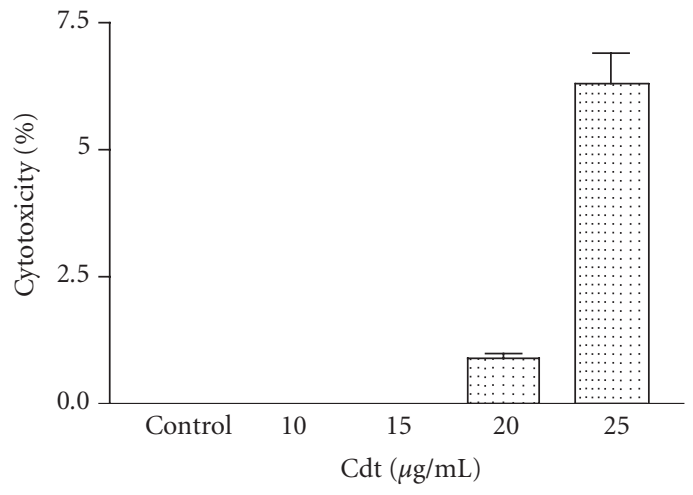

(a)

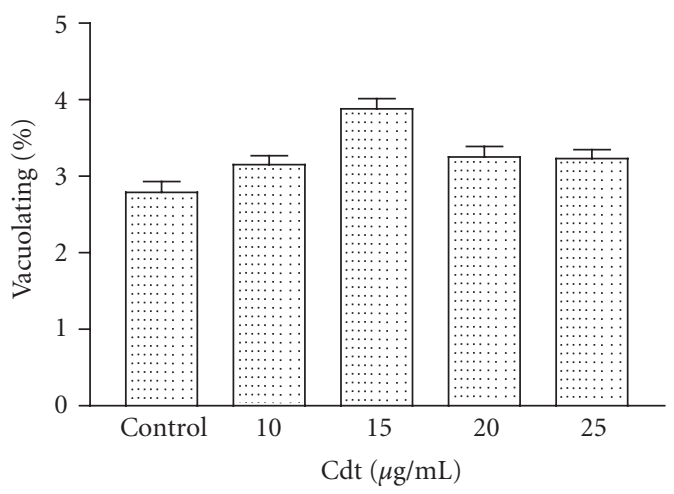

(c)

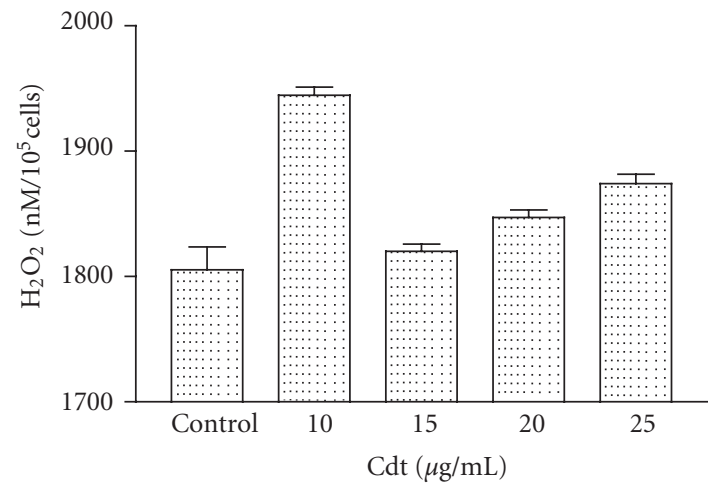

(b)

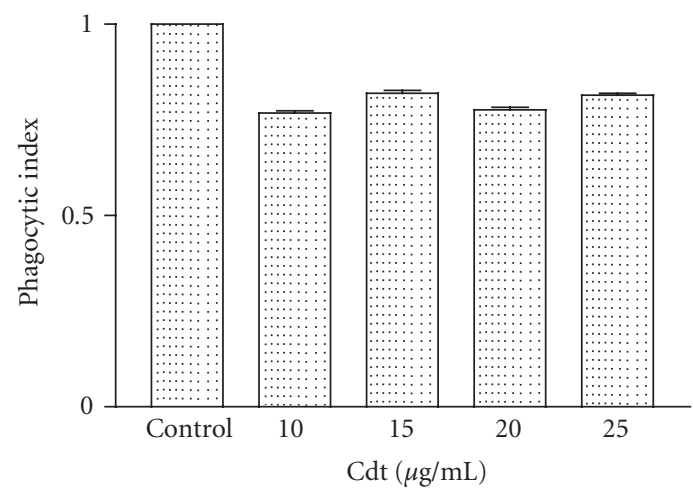

(d)

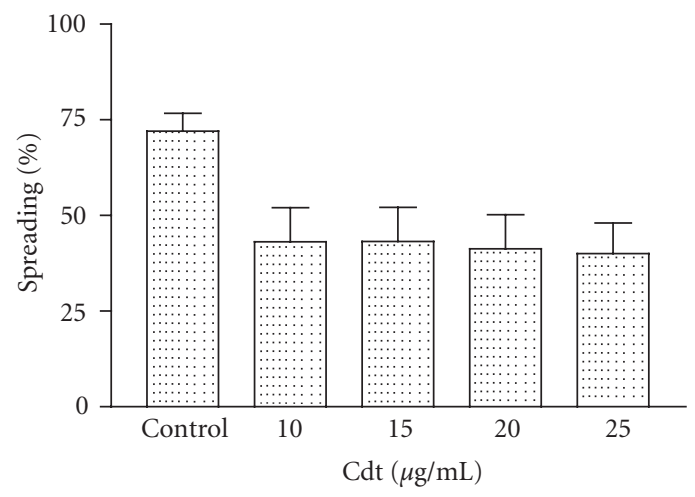

(e)

FIGURE 1. Effect of Cdt on macrophage activation. Groups of BALB/c female mice were sacrificed and their peritoneal macrophages collected and exposed in vitro to different amounts of Cdt. After different times of incubation of the cultured peritoneal macrophages, the cytotoxic and vacuolating percentages were determined at 24 hours; the levels of $\mathrm{H}_{2} \mathrm{O}_{2}$ and phagocytic index were determined at 48 hours; spreading percentage was determined at 12 hours. Each point represents the mean value of samples from five experiments in different groups of five mice. Statistical differences between the treatments were $P>.01$.

with L929 cells, a fibroblast continuous cell line was used as described previously by Ruff and Gifford [30]. The percentage cytotoxicity was calculated as follows: $\left(A_{\text {control }}-\right.$ $\left.A_{\text {sample }} / A_{\text {control }}\right) \times 100$.

\section{Statistical analysis}

Data are expressed as the mean \pm standard deviation. Statistical analyses were performed by Student $t$-test and the level of significance was set at $P<.05$.

\section{RESULTS}

\section{Effect of Cdt on in vitro activation}

The effects of different doses of Cdt were analyzed by detecting levels of cytotoxicity, $\mathrm{H}_{2} \mathrm{O}_{2}$, vacuole formation, phagocytic index, and spreading percentage in macrophages as summarized in Figure 1. Groups of mice were sacrificed and their macrophages, which were collected using peritoneal lavage, were then exposed in vitro 
to different amounts of Cdt and incubated under the same conditions for different time periods. For all experiments when $5 \mu \mathrm{g} / \mathrm{mL}$ of Cdt were used, the results observed were similar to those obtained for the culture control (result not shown). Macrophages exposed over 24 hours to $1-20 \mu \mathrm{g} / \mathrm{mL}$ of Cdt do not cause lyses. In contrast, the highest cytotoxicity percentage was observed in macrophages exposed to $25 \mu \mathrm{g} / \mathrm{mL}$ (Figure 1). The highest levels of $\mathrm{H}_{2} \mathrm{O}_{2}$ were observed 48 hours postexposure, in macrophage cultures treated with $10 \mu \mathrm{g} / \mathrm{mL}$ of Cdt (Figure 1). All the Cdt amounts were capable of stimulating vacuole formation in macrophages exposed to $\mathrm{Cdt}$ over 24 hours (Figure 1). The highest vacuolating percentage was observed for macrophage groups exposed to $15 \mu \mathrm{g} / \mathrm{mL}$ of Cdt. Figure 1 also shows that Cdt was capable of inhibiting phagocytosis and spreading percentage. The phagocytic index and spreading percentage presented by macrophages exposed to Cdt for 48 and 12 hours, respectively, were significantly lower when compared with control culture (Figure 1).

The NO and cytokine production in macrophages exposed to different amounts of venom are illustrated in Figure 2. The levels of IL-6, TNF, and IFN- $\gamma$ were highest in macrophage groups exposed to Cdt for 12, 48, and 96 hours, respectively, when compared with macrophage control (Figure 2). Interestingly, among the groups of cells exposed to Cdt, the maximum levels of IL-6, TNF, and IFN- $\gamma$ were observed with $10 \mu \mathrm{g} / \mathrm{mL}$ (Figure 2). Figure 2 also shows that no difference was observed for levels of IL-10 among all groups of macrophages exposed to Cdt. Moreover, for all cytokines studied here, with exception of IL-10, a discreet decrease was observed, when the amount of Cdt was increased. The highest levels of NO were observed among macrophages exposed to $15 \mu \mathrm{g} / \mathrm{mL}$ of Cdt for 96 hours (Figure 2).

Taking these results, it was possible to establish the optimal conditions for macrophage exposure to Cdt. Thus in the following set of experiments, the macrophages were exposed to $10 \mu \mathrm{g} / \mathrm{mL}$ of Cdt.

\section{Effect of Cdt on functional status}

To evaluate the functional status of macrophages, mice were sacrificed and their macrophages collected using peritoneal lavage. Those were then exposed to $10 \mu \mathrm{g} / \mathrm{mL}$ of Cdt. The effects of venom on macrophages were determined by measuring oxygen intermediate metabolites, phagocytic index, and percentage of spreading (Figure 3). The highest levels of $\mathrm{H}_{2} \mathrm{O}_{2}$ were observed among macrophages exposed to Cdt over a 48-hours period, when compared with those obtained from control cells $(P>.05)$ (Figure 3$)$. In this case, the activation was not confirmed using the phagocytic index. For macrophage groups treated with Cdt for 2 hours the phagocytic index was significantly lower, when compared with those obtained from control cultures $(P>.001)$ (Figure 3). The highest phagocytic index was observed for macrophages exposed to Cdt for 12 hours, which thereafter decayed (Figure 3). After 48 hours, the phagocytic index remained constant (results not shown).

The spreading test is based on the ability of macrophages, which have been activated, to adhere to plastic and to spread. Macrophages exposed to $10 \mu \mathrm{g} / \mathrm{mL}$ of Cdt presented a significantly lower percentage spreading, when compared with those obtained from control macrophages $(P>.001)$ (Figure 3$)$. For macrophages treated with Cdt, it was also observed that the percentage of spreading presented a discrete increment with an increase in the time that they were exposed to Cdt for up to 72 hours, decaying thereafter (Figure 3).

\section{Effect of Cdt on vacuole formation}

In order to determine the vacuolation in macrophage, cells were obtained as described above. The extent of vacuolation was quantified over a period of 12 hours up to 120 hours, using neutral red assay. As shown in Figure 4 , the vacuolating percentage was discretely higher for macrophages exposed to Cdt for 48 hours, when compared with those obtained from control cultures. The vacuoles started to appear at 12 hours until 48 hours after addition of Cdt at $10 \mu \mathrm{g} / \mathrm{mL}$, decaying thereafter (Figure 4).

\section{Effect of Cdt on mediators production}

To evaluate the ability of Cdt to induce the production and liberation of NO and cytokines, groups of mice were sacrificed and their macrophages, which were collected by peritoneal lavage, were exposed in vitro to $10 \mu \mathrm{g} / \mathrm{mL}$ of Cdt for different time periods.

As shown in Figure 5, the levels of NO of the macrophages in vitro exposed to Cdt increased up to 96 hours, decreasing thereafter. The levels of NO in the groups of macrophages exposed to $\mathrm{Cdt}$ were significantly higher than those obtained from control cultures $(P>.01)$.

The kinetics of cytokines production is shown in Figure 5. The in vitro exposition of macrophages to $\mathrm{Cdt}$ resulted in IL-6 production. The maximum production of IL-6 was detected among cultures exposed for 24 hours (Figure 5). TNF production was significantly higher for macrophages exposed to Cdt for 48 hours $(P>.001)$ (Figure 5). Figure 5 also shows that the levels of IFN$\gamma$ started to appear after 48 hours in macrophage groups exposed to Cdt. The maximum levels of IFN $-\gamma$ were observed in cultures exposed to Cdt for 96 hours (Figure 5). With respect to IL-10, two peaks were observed, one of them at 48 hours and the second one at 96 hours (Figure 5). Although macrophages exposed to Cdt presented an increase in IL-10 levels, these increments displayed no difference, when compared with those obtained from control cultures (Figure 5).

\section{DISCUSSION}

In Brazil, $C$ durissus terrificus is responsible for the majority of accidents among humans. Snake venoms have been shown to consist of a mixture of many toxic proteins 


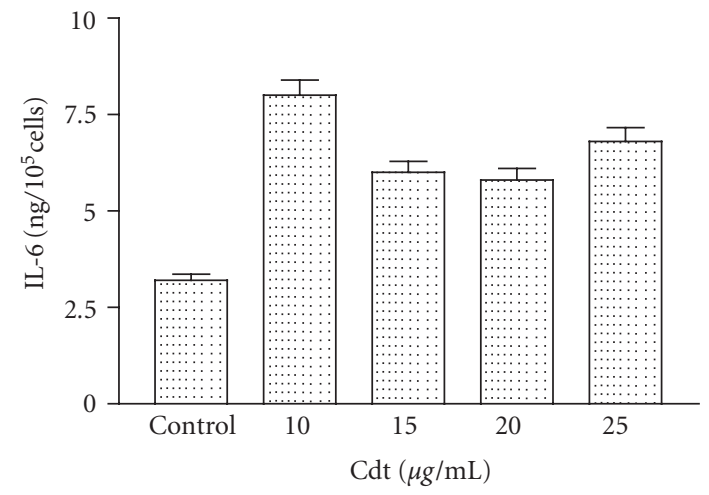

(a)

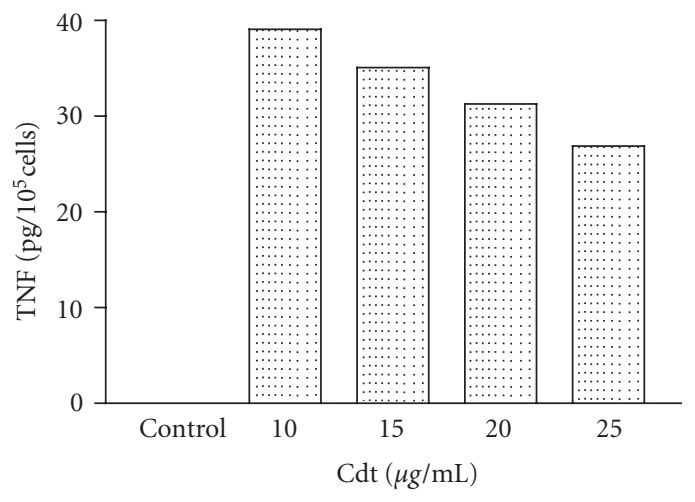

(c)

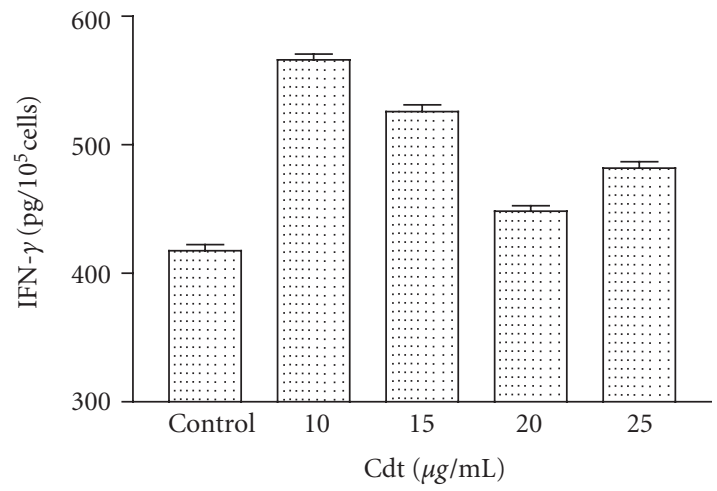

(b)

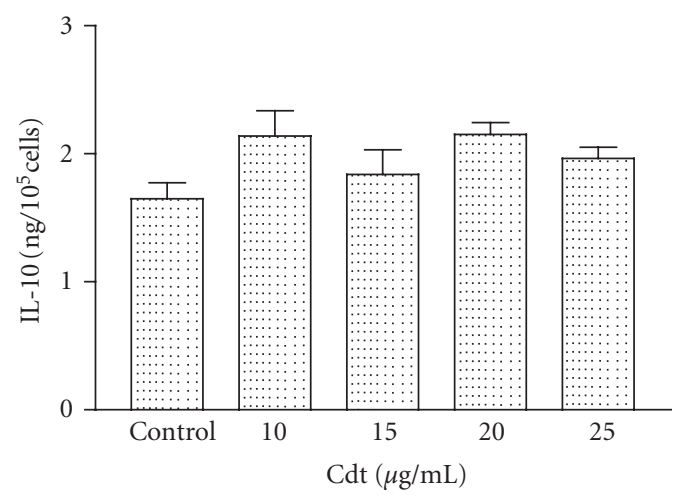

(d)

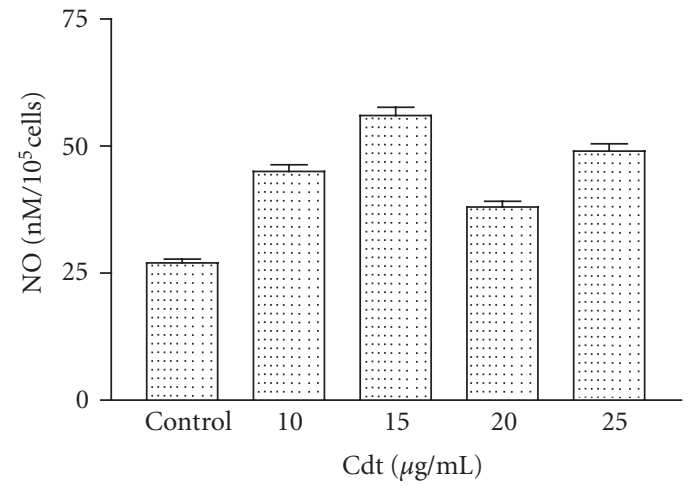

(e)

FIGURE 2. Mediators released by peritoneal macrophages from BALB/c female mice. Peritoneal macrophages were obtained and exposed in vitro to different amounts of Cdt as described in "materials and methods." The levels of IL-6 were determined after 24 hours, for IL-10 and IFN- $\gamma$ after 72 hours. They were assayed by ELISA assay using monoclonal antibodies as the probe. TNF levels were determined after 48 hours by standard assay with L929 cells. NO levels were determined after 96 hours by the Griess colorimetric reaction. Each point represents the mean value of samples from five experiments in different groups of five mice. Statistical differences between the treatments were $P>.01$.

and enzymes, with diverse and complex pharmacological effects. Despite increasing knowledge concerning the pathophysiology events following snake envenoming, the inflammatory response has scarcely been investigated.

Macrophages are a critical part of immune response and play a fundamental role in both humoral and cellu- lar immune responses. The macrophages function as effectors cells because they are able to rapidly recognize, internalize, and destroy a large number of pathogens, or they may act as accessory cells, recruiting and activating other immune cells. The present antigens to lymphocytes, modulate $\mathrm{T}$ cell functions, and secrete a large number of 


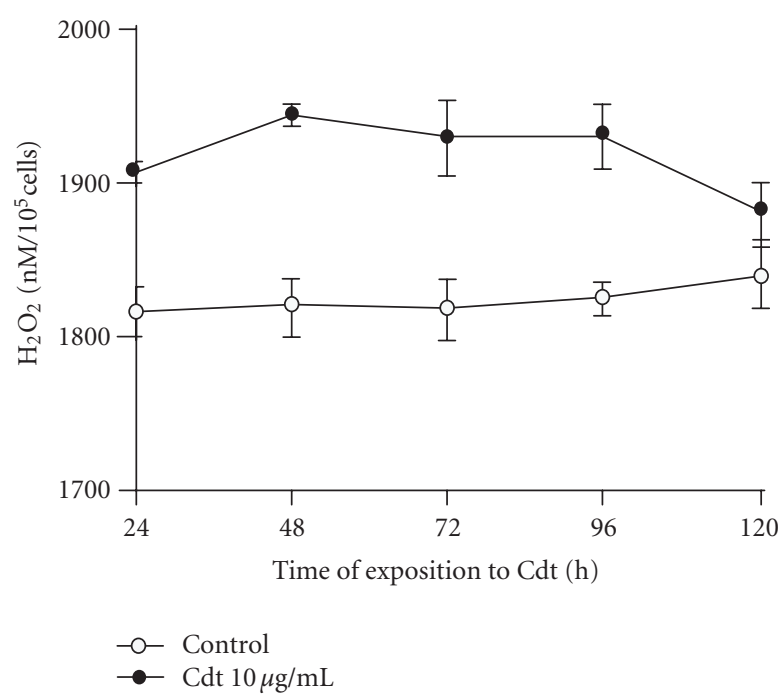

(a)

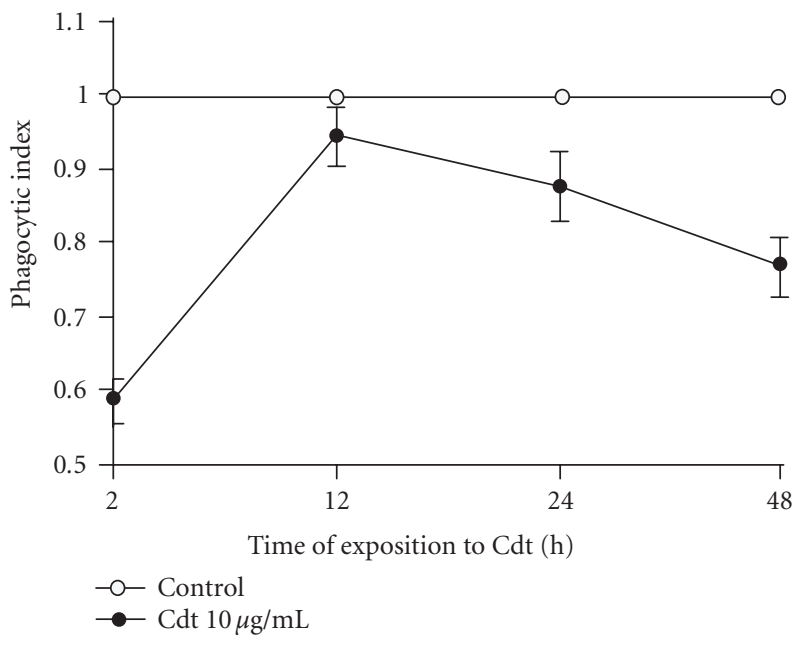

(b)

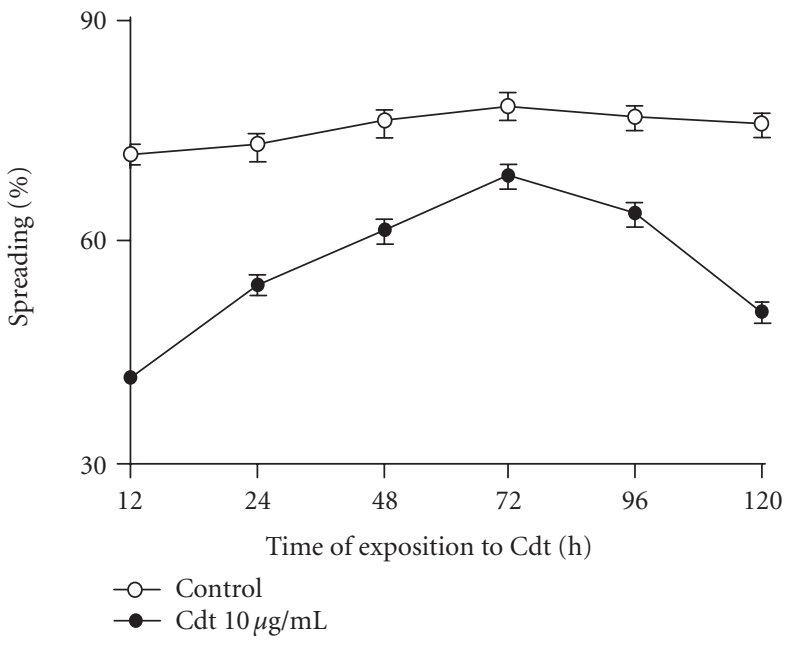

(c)

Figure 3. Functional status of macrophages. Peritoneal macrophages were obtained and exposed in vitro to $10 \mu \mathrm{g} / \mathrm{mL}$ of Cdt for different times as described in "materials and methods." The activation of the cultured peritoneal macrophages was determined by measuring the oxygen intermediates metabolites $\left(\mathrm{H}_{2} \mathrm{O}_{2}\right)$. The phagocytic index and percentage spreading were determined as described above. Each point represents the mean value of samples from five experiments in different groups of five mice. Statistical differences between the treatments were $P>.01$.

inflammatory mediators, which play roles in the amplification of both humoral and cell-mediated immune responses $[31,32,33]$.

In order to establish the optimal conditions for macrophage-venom interactions, the effects of Cdt on cytotoxicity percentage were studied. This study showed that $5-15 \mu \mathrm{g} / \mathrm{mL}$ of Cdt did not induce cytotoxicity in peritoneal macrophages from BALB/c mice. The highest cytotoxicity percentage was observed in cultures of macrophages exposed to $25 \mu \mathrm{g} / \mathrm{mL}$ of Cdt.

The macrophages exhibit different phenotypes, which are mostly related to their cell morphology, surface antigen expression, and function. This phenotypic heterogeneity is a consequence of a series of down-regulations of certain cellular processes and the up-regulation of others $[34,35]$. This study shows that Cdt induced the morphological changes in macrophages and that these changes were not dose-dependent on the venom used.

Particles internalization by macrophages and other phagocytic cells results in the generation of phagocytic vacuoles. The typical characteristic of such vacuoles is their progressive maturation along the endocytic pathway, leading to fusion with late endosomes and ultimately lysosomes, where ingested material is degraded $[36,37]$. In this study we observed the presence of vacuoles after $10 \mu \mathrm{g} / \mathrm{mL}$ of Cdt exposure. We also observed that the presence of large vacuoles and membrane projections were not damaging. The cells presented plasma 


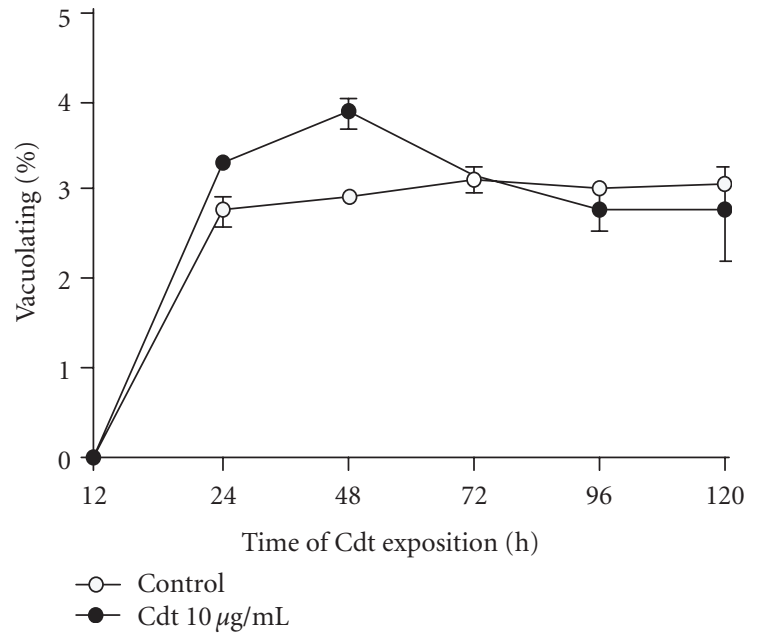

Figure 4. Vacuole formation. Peritoneal macrophages were obtained and exposed in vitro to $10 \mu \mathrm{g} / \mathrm{mL}$ of Cdt as described in "materials and methods." After different periods of incubation at $37^{\circ} \mathrm{C}$ in an atmosphere of $5 \% \mathrm{CO}_{2}$, the cells were stained with neutral red for 5 minutes. The absorbance was determined at $540 \mathrm{~nm}$, and the results were expressed as described before. Each point represents the mean value of samples from five experiments in different groups of five mice. Statistical differences between the treatments were $P>.01$.

membrane integrity and well-preserved mitochondria profiles, characteristic of good cell viability. Previous authors have shown that the increased number of vacuoles during stimulation was probably due to the increased exocytosis of inflammatory proteins, which could be detected in their culture supernatants [38].

The particles which are ingested by phagocytic cells through a receptor-mediated mechanism involve extensive cytoskeleton rearrangements and membrane remodeling [39]. The results obtained in this study have shown that the Cdt induced a decreasing phagocytic index. These observations are in accordance with other authors who have described macrophage exposition to Cdt venom $[21,22]$.

The present study evaluates the spreading ability of macrophages. Those nonexposed to venom obtained between $72 \%$ up to $76 \%$ ratio of macrophage spreading. In contrast, among macrophages exposed to Cdt, the spreading percentage was about $44 \%$. Under the conditions used in the present study, Cdt demonstrated a significant inhibitory effect on macrophage spreading which was also related to modest activation. These results suggest that the concentration of Cdt did not directly effect variations in the levels of $\mathrm{H}_{2} \mathrm{O}_{2}$ released by peritoneal macrophages. Since spreading is an important mechanism in the interaction between the phagocyte and the particle to be engulfed, any substance which inhibits macrophage spreading, also interferes with the phagocytosis process $[21,22]$.

The appearance and activation of macrophages are stages on the path to rapid events, responsible for the development of many pathological lesions. A number of stimuli such as microbial infection, tissue injury, and tumor cells can activate macrophages. In culture, the macrophages provide the secretion of various substances, and biological activity can vary from induction of cell growth to cell death. To define the optimal conditions for macrophage exposure to Cdt, inflammatory responses in the mouse model were investigated. Cytokines are a group of regulatory and immunomodulatory proteins involved in a number of physiological processes. With respect to the proinflammatory cytokines, they induce local and systemic inflammatory manifestations. These last manifestations include fever, an acute-phase response, and the induction of systemic shock in severe inflammatory response. The proinflammatory cytokines are the principal mediators of the inflammatory response. Previous studies have shown that proinflammatory cytokines such as IL-1, IL-6, and TNF [40, 41, 42] are key intermediates of an over-responsive host-response reaction. TNF exerts a wide spectrum of biological activities which contributes to the pathophysiology of septic shock and probably contributes to systemic inflammatory response in envenomated mice [11].

Under the conditions used in the present study, we observed that the exposure of macrophages to Cdt may alter TNF production. TNF production peaked after 48 hours, decaying thereafter, whereas IL- 6 peaked after 24 hours. The decrease of IL- 6 and TNF levels after 24 and 48 hours, respectively, has also been observed by other authors $[8,9,10,11]$. Thus these results show that the murine macrophages exposed to Cdt are stimulated to produce the proinflammatory acute-phase cytokines, TNF, and IL6. The induction of these proinflammatory cytokines by macrophages in response to Cdt may be an important factor in the pathogenesis induced by this venom. Another point demonstrated by this study was the observation that the phagocytic index was lower in culture macrophage treated with Cdt. Inhibition of phagocytosis was not accompanied by a decrease in the release of TNF and IL- 6 . IFN- $\gamma$ is a key cytokine in host defenses against intracellular organism [43]. The present study shows that Cdt is capable of stimulating murine peritoneal macrophage to release IFN- $\gamma$. IL-10 is a pleiotropic cytokine recognized for its inhibitory activity on a variety of immune functions. IL-10 exerts anti-inflammatory effects on macrophages and dendritic cells by suppressing production of inflammatory cytokines such as TNF- $\alpha$, IL-1, and IL-6. Among all cytokines analyzed in this study, only IL-10, which is a product of macrophages exposed to Cdt was not altered.

It has been suggested that overproduction of inflammatory cytokines has been, may be, a major factor in several diseases associated with tissue damage. The ratios of IL-10/TNF and IL-6/IL-10 indicate the inflammatory status of the cells. The results obtained in this study showed that the IL-6/IL-10 ratio could possibly reflect the balance between pro- and anti-inflammatory cytokines in macrophages, which may represent inflammatory status 


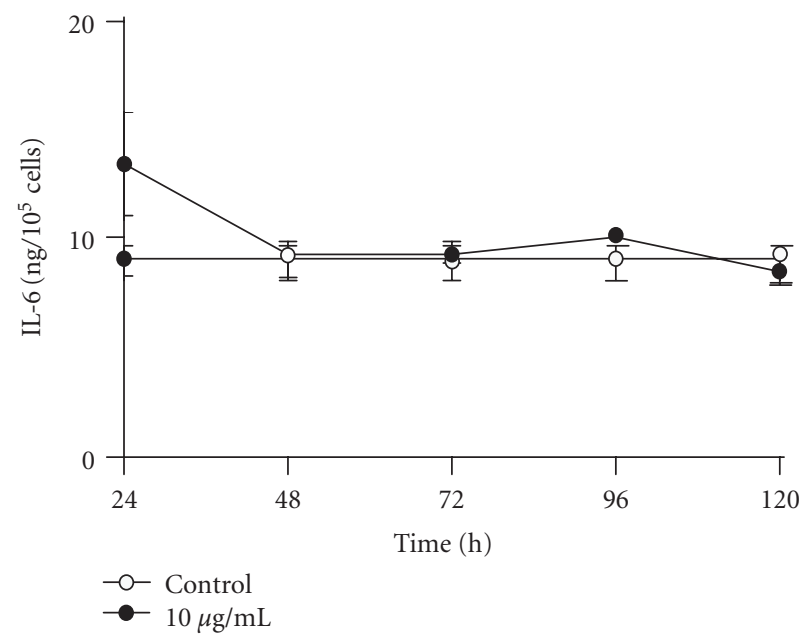

(a)

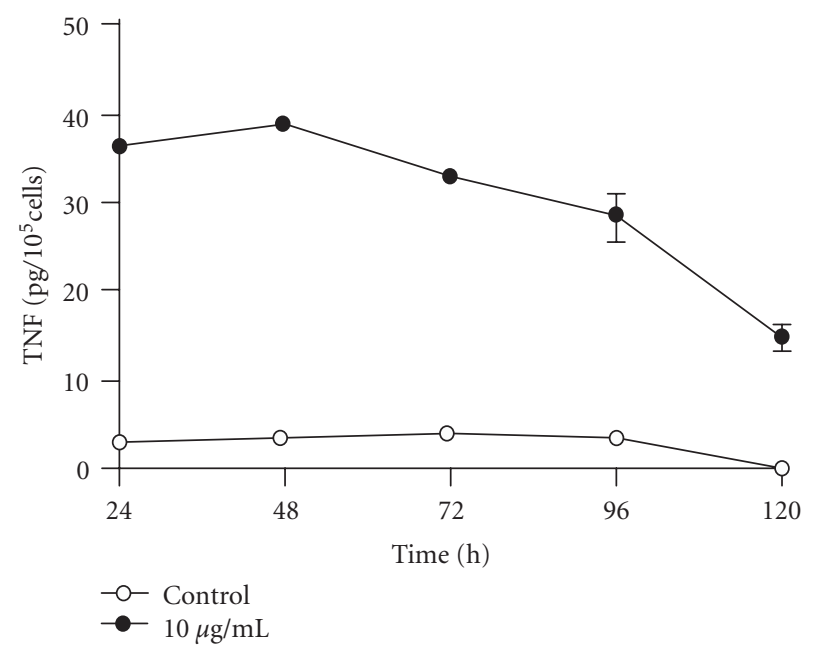

(c)

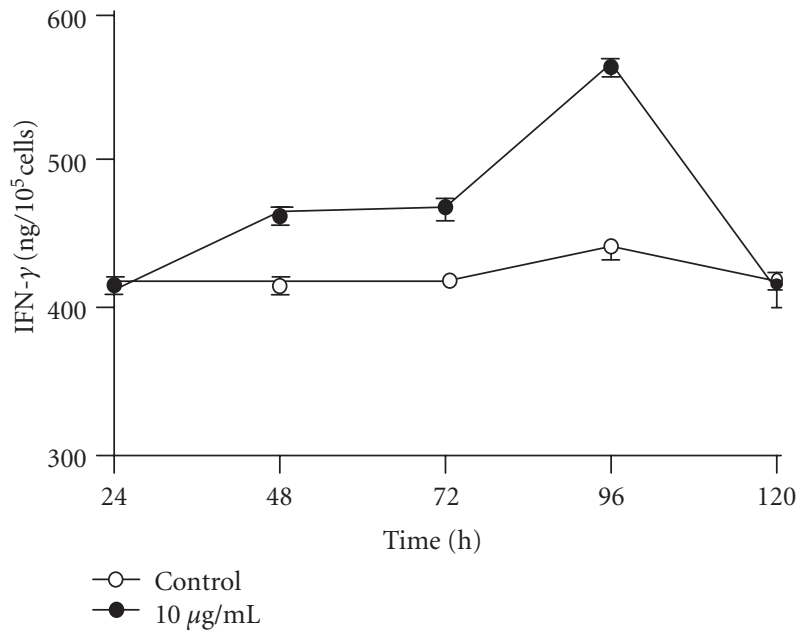

(b)

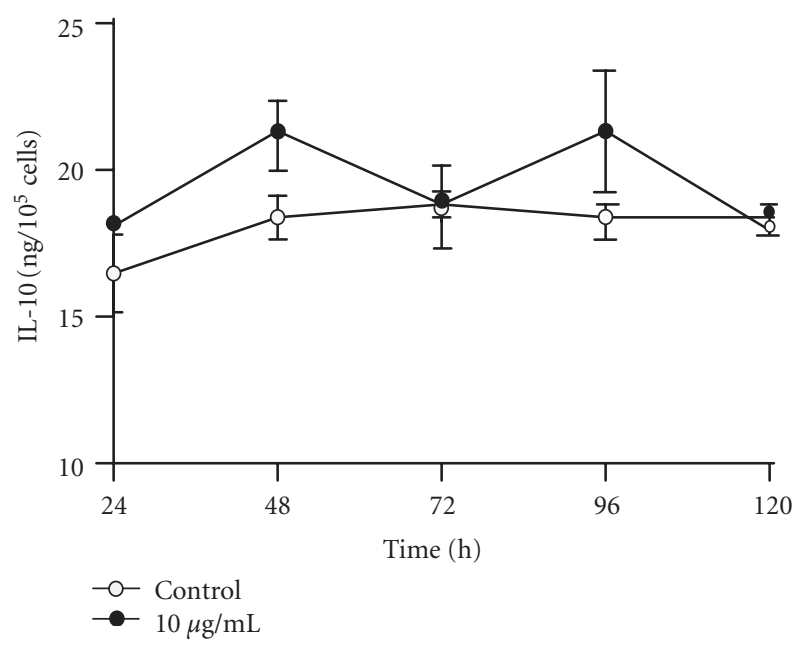

(d)

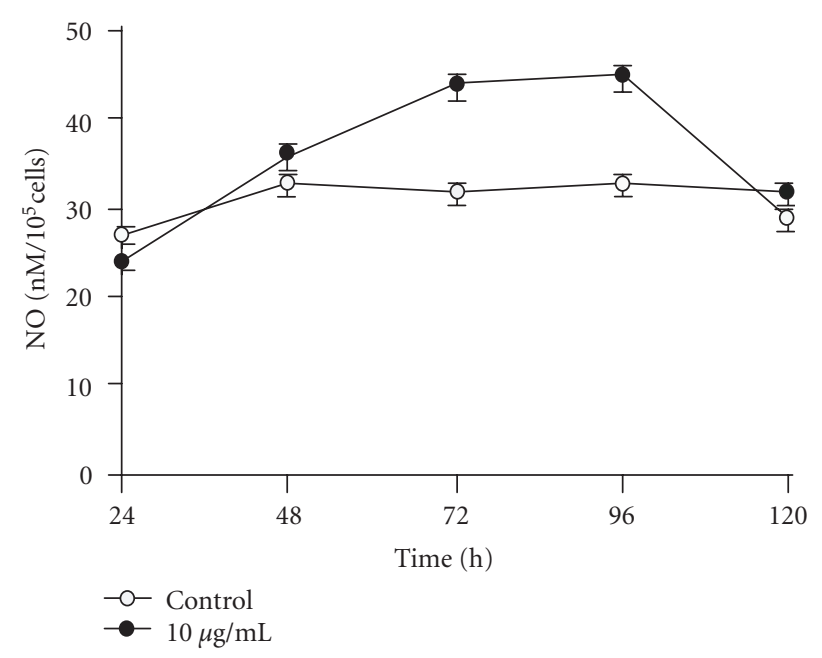

(e)

Figure 5. Cytokines released by peritoneal macrophages from BALB/c mice. Peritoneal macrophages were obtained and exposed in vitro to $10 \mu \mathrm{g} / \mathrm{mL}$ of Cdt for different periods of time as described in "materials and methods." IL-6, IL-10, and IFN- $\gamma$ were assayed by ELISA using monoclonal antibodies as the probe. TNF levels were determined by standard assay with L929 cells. NO levels were detected by the Griess colorimetric reaction. Each point represents the mean value of samples from five experiments in different groups of five mice. Statistical differences between the treatments were $P>.01$. 
in envenoming processes. Low IL-10 secretion was observed in those macrophages treated with Cdt because they are unable to mount the anti-inflammatory response.

$\mathrm{NO}$ is an inflammatory mediator directly related to cell activation which contributes to the death or inhibition of a variety of pathogens $[44,45]$. The present study showed that Cdt is capable of inducing NO production in peritoneal macrophages. These results agree with previous reports which showed that macrophages exposed to a variety of snakes venoms have significantly enhanced $\mathrm{NO}$ production $[8,9,11]$.

However, the exact mechanism by which this overproduction of inflammatory mediators takes place is not completely understood. In conclusion, it is clear that macrophages exposed to Cdt exhibit morphological changes and differential levels of activation, which may also indicate an exaggeration of proinflammatory activity coupled with an inadequate anti-inflammatory compensation.

\section{ACKNOWLEDGMENTS}

This work was supported by Secretaría de Educación Publica (SEP-PROMEP), Mexico. The authors thank Dr Carlos Peña and Dr Martin Patiño Vera for critical review of the manuscript.

\section{REFERENCES}

[1] Kamiguti AS, Cardoso JL. Haemostatic changes caused by the venoms of South American snakes. Toxicon. 1989;27(9):955-963.

[2] Oshima-Franco Y, Hyslop S, Prado-Franceschi J, Cruz-Hofling MA, Rodrigues-Simioni L. Neutralizing capacity of antisera raised in horses and rabbits against Crotalus durissus terrificus (South American rattlesnake) venom and its main toxin, crotoxin. Toxicon. 1999;37(10):1341-1357.

[3] Rodríguez Acosta A, Uzcategui W, Aguaje R, Aguilar I, Giron ME. Analisis clinico y epidemiologico de los accidentes por mordeduras de serpientes del genero Bothrops en Venezuela [A clinical and epidemiological analysis of accidental bites by snakes of the genus Bothrops in Venezuela]. Rev Cubana Med Trop. 2000;52(2):90-94.

[4] Pulido-Mendez M, Rodríguez-Acosta A, Finol HJ, Aguilar I, Giron ME. Ultrastructural pathology in skeletal muscle of mice envenomed with Crotalus vegrandis venom. J Submicrosc Cytol Pathol. 1999;31(4): 555-561.

[5] Rodríguez-Acosta A, Pulido-Mendez M, Finol HJ, Giron ME, Aguilar I. Liver ultrastructural pathology in mice envenomed with Uracoan rattlesnake (Crotalus vegrandis) venom. J Submicrosc Cytol Pathol. 1999;31(3):433-439.

[6] Chippaux JP, Williams V, White J. Snake venom variability: methods of study, results and interpretation. Toxicon. 1991;29(11):1279-1303.
[7] Lomonte B, Gutierrez JM, Romero M, Nunez J, Tarkowski A, Hanson LA. An MTT-based method for the in vivo quantification of myotoxic activity of snake venoms and its neutralization by antibodies. $J$ Immunol Methods. 1993;161(2):231-237.

[8] Barros SF, Friedlanskaia I, Petricevich VL, Kipnis TL. Local inflammation, lethality and cytokine release in mice injected with Bothrops atrox venom. Mediators Inflamm. 1998;7(5):339-346.

[9] Petricevich VL, Teixeira CF, Tambourgi DV, Gutierrez JM. Increments in serum cytokine and nitric oxide levels in mice injected with Bothrops asper and Bothrops jararaca snake venoms. Toxicon. 2000;38(9):1253-1266.

[10] Tambourgi DV, Petricevich VL, Magnoli FC, Assaf SL, Jancar S, Dias Da Silva W. Endotoxemic-like shock induced by Loxosceles spider venoms: pathological changes and putative cytokine mediators. Toxicon. 1998;36(2):391-403.

[11] Petricevich VL. Cytokine and nitric oxide production following severe envenomation. Curr Drug Targets Inflamm Allergy. 2004;3(3):325-332.

[12] van Dissel JT, van Langevelde P, Westendorp RG, Kwappenberg K, Frolich M. Anti-inflammatory cytokine profile and mortality in febrile patients. Lancet. 1998;351(9107):950-953.

[13] Taniguchi T, Koido Y, Aiboshi J, Yamashita T, Suzaki S, Kurokawa A. The ratio of interleukin-6 to interleukin-10 correlates with severity in patients with chest and abdominal trauma. Am J Emerg Med. 1999;17(6):548-551.

[14] Coffman RL, Mosmann TR. CD4 + T-cell subsets: regulation of differentiation and function. Res Immunol. 1991;142(1):7-9.

[15] Jo T, Terada N, Takauchi Y, et al. Cytotoxic actions of cytokines on cultured mouse luteal cells are independent of nitric oxide. J Steroid Biochem Mol Biol. 1995;55(3-4):291-296.

[16] Stein M, Gordon S. Regulation of tumor necrosis factor (TNF) release by murine peritoneal macrophages: role of cell stimulation and specific phagocytic plasma membrane receptors. Eur J Immunol. 1991;21(2):431-437.

[17] Van der Meide PH, Schellekens H. Cytokines and the immune response. Biotherapy. 1996;8(3-4):243-249.

[18] Gerard C, Bruyns C, Marchant A, et al. Interleukin 10 reduces the release of tumor necrosis factor and prevents lethality in experimental endotoxemia. $J$ Exp Med. 1993;177(2):547-550.

[19] Howard M, Muchamuel T, Andrade S, Menon S. Interleukin 10 protects mice from lethal endotoxemia. J Exp Med. 1993;177(4):1205-1208.

[20] Cardoso DF, Mota I. Effect of Crotalus venom on the humoral and cellular immune response. Toxicon. 1997;35(4):607-612. 
[21] Sampaio SC, Brigatte P, Sousa-e-Silva MC, et al. Contribution of crotoxin for the inhibitory effect of Crotalus durissus terrificus snake venom on macrophage function. Toxicon. 2003;41(7):899907.

[22] Sampaio SC, Sousa-e-Silva MC, Borelli P, Curi R, Cury Y. Crotalus durissus terrificus snake venom regulates macrophage metabolism and function. $J$ Leukoc Biol. 2001;70(4):551-558.

[23] International Society on Toxicology. Toxicon. 1992; 30:1-12.

[24] Cohn ZA, Benson B. The differentiation of mononuclear phagocytes: morphology, cytochemistry, and biochemistry. J Exp Med. 1965;121:153-170.

[25] Pick E, Mizel D. Rapid microassays for the measurement of superoxide and hydrogen peroxide production by macrophages in culture using an automatic enzyme immunoassay reader. I Immunol Methods. 1981;46(2):2111-2126.

[26] Zebedee SL, Koduri RK, Mukherjee J, et al. Mousehuman immunoglobulin G1 chimeric antibodies with activities against Cryptococcus neoformans. Antimicrob Agents Chemother. 1994;38(7):1507-1514.

[27] Arruda MS, Richini VB, Oliveira SM, VilaniMoreno FR. Experimental murine mycobacteriosis: evaluation of the functional activity of alveolar macrophages in thalidomide-treated mice. Braz J Med Biol Res. 2004;37(4):485-492.

[28] Keller R, Keist R, Wechsler A, Leist TP, van der Meide PH. Mechanisms of macrophage-mediated tumor cell killing: a comparative analysis of the roles of reactive nitrogen intermediates and tumor necrosis factor. Int J Cancer. 1990;46(4):682-686.

[29] Schumacher JH, O'Garra A, Shrader B, et al. The characterization of four monoclonal antibodies specific for mouse IL-5 and development of mouse and human IL-5 enzyme-linked immunosorbent. J Immunol. 1988;141(5):1576-1581.

[30] Ruff MR, Gifford GE. Purification and physicochemical characterization of rabbit tumor necrosis factor. J Immunol. 1980;125(4):1671-1677.

[31] Nathan CF. Secretory products of macrophages. J Clin Invest. 1987;79(2):319-326.

[32] Jedynak M, Siemiatkowski A. The role of monocytes/macrophages and their cytokines in the development of immunosuppression after severe injury. Pol Merkuriusz Lek. 2002;13(75):238-241.

[33] Adams DO, Hamilton TA. The cell biology of macrophage activation. Annu Rev Immunol. 1984;2:283318.

[34] Barth MW, Hendrzak JA, Melnicoff MJ, Morahan PS. Review of the macrophage disappearance reaction. J Leukoc Biol. 1995;57(3):361-367.

[35] Arandjelovic S, Bogic M, Raskovic S. The role of mononuclear phagocytes and dendritic cells in allergic inflammation. Srp Arh Celok Lek. 1998;126(12):46-53.
[36] Desjardins M, Celis JE, van Meer G, et al. Molecular characterization of phagosomes. J Biol Chem. 1994; 269(51):32194-32200.

[37] Russell DG. Mycobacterium and Leishmania: stowaways in the endosomal network. Trends Cell Biol. 1995;5(3):125-128.

[38] Nacife VP, Soeiro M de N, Gomes RN, D’Avila H, Castro-Faria Neto HC, Meirelles M de N. Morphological and biochemical characterization of macrophages activated by carrageenan and lipopoly- saccharide in vivo. Cell Struct Funct. 2004;29 (2):27-34.

[39] Aderem A, Underhill DM. Mechanisms of phagocytosis in macrophages. Annu Rev Immunol. 1999; 17:593-623.

[40] Akira S, Hirano T, Taga T, Kishimoto T. Biology of multifunctional cytokines: IL-6 and related molecules (IL-1 and TNF). FASEB J. 1990;4(11): 2860-2867.

[41] Beutler B. TNF, immunity and inflammatory disease: lessons of the past decade. I Investig Med. 1995;43(3):227-235.

[42] Dinarello CA. The proinflammatory cytokines interleukin-1 and tumor necrosis factor and treatment of the septic shock syndrome. J Infect Dis. 1991;163(6):1177-1183.

[43] Kaufmann SH. Immunity to intracellular bacteria. Annu Rev Immunol. 1993;11:129-163.

[44] Nathan ÇF, Hibbs JB Jr. Role of nitric oxide synthesis in macrophage antimicrobial activity. Curr Opin Immunol. 1991;3(1):65-70.

[45] Nathan Ç, Xie QW. Nitric oxide synthases: roles, tolls, and controls. Cell. 1994;78(6):915-918. 


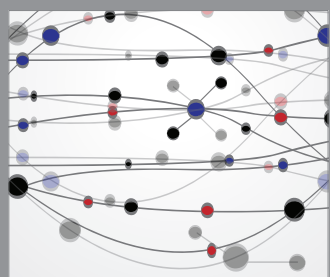

The Scientific World Journal
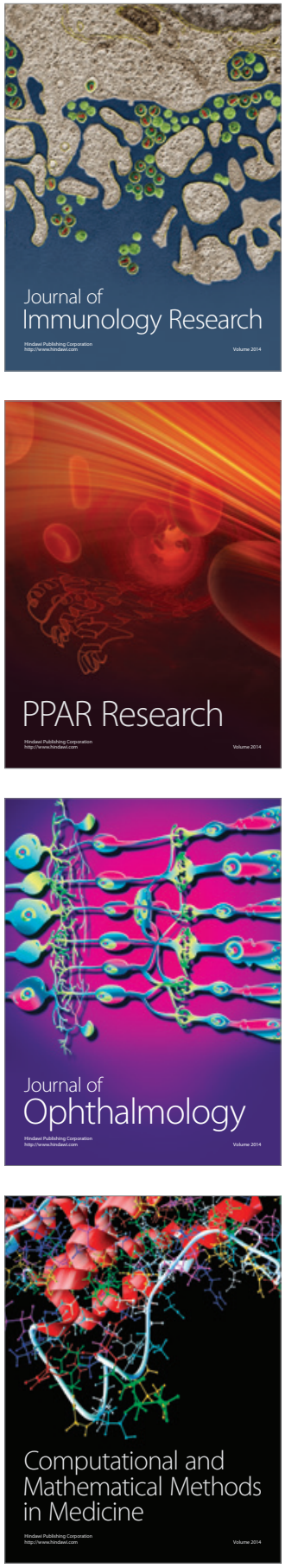

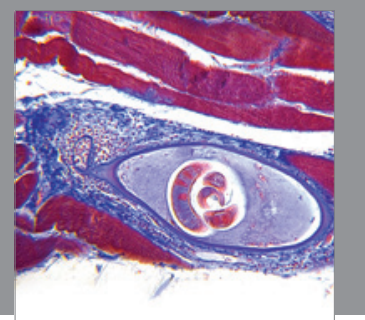

Gastroenterology

Research and Practice
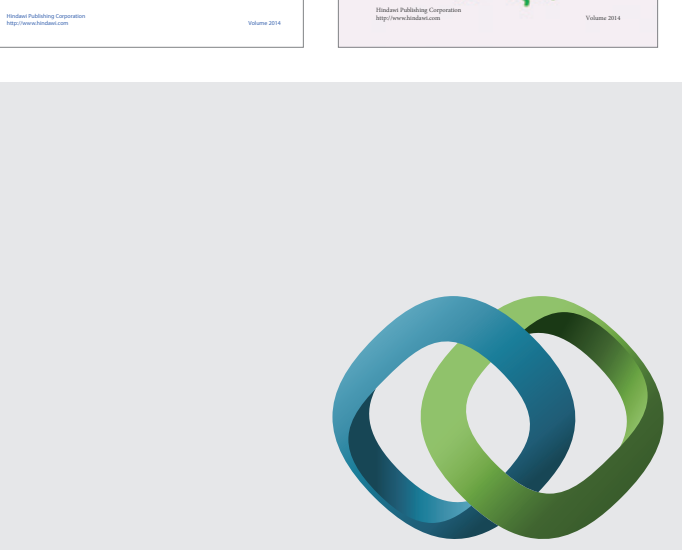

\section{Hindawi}

Submit your manuscripts at

http://www.hindawi.com
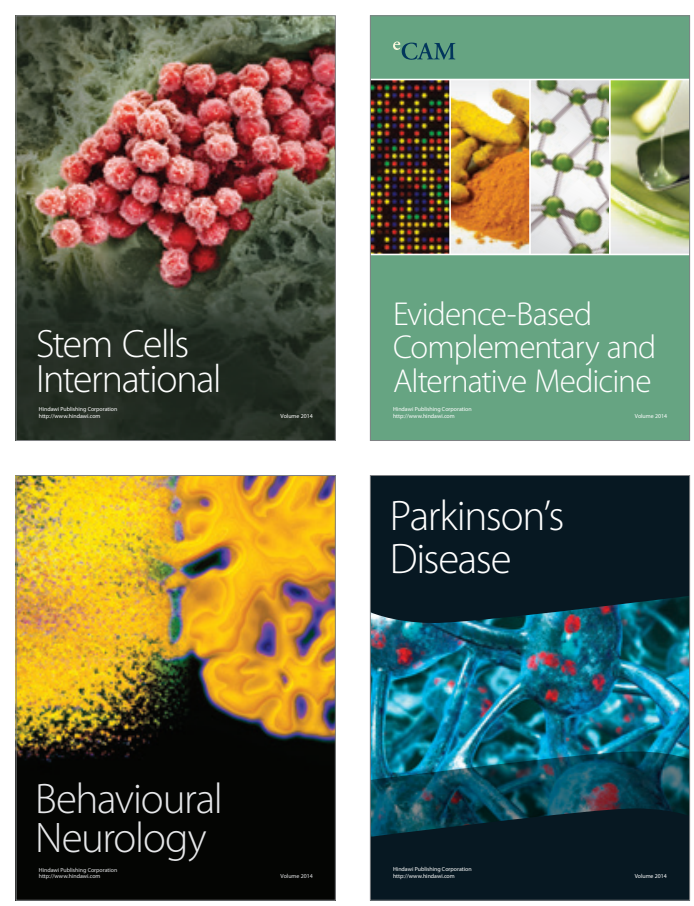

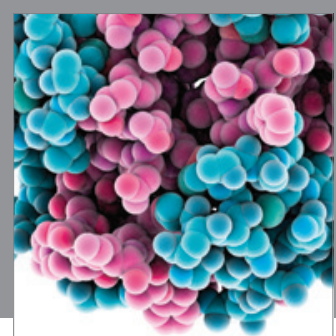

Journal of
Diabetes Research

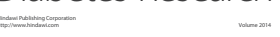

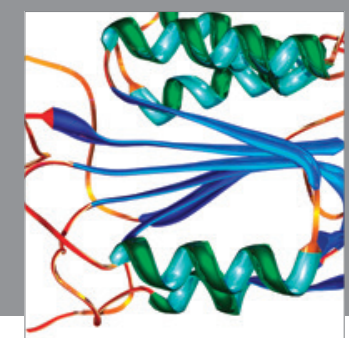

Disease Markers
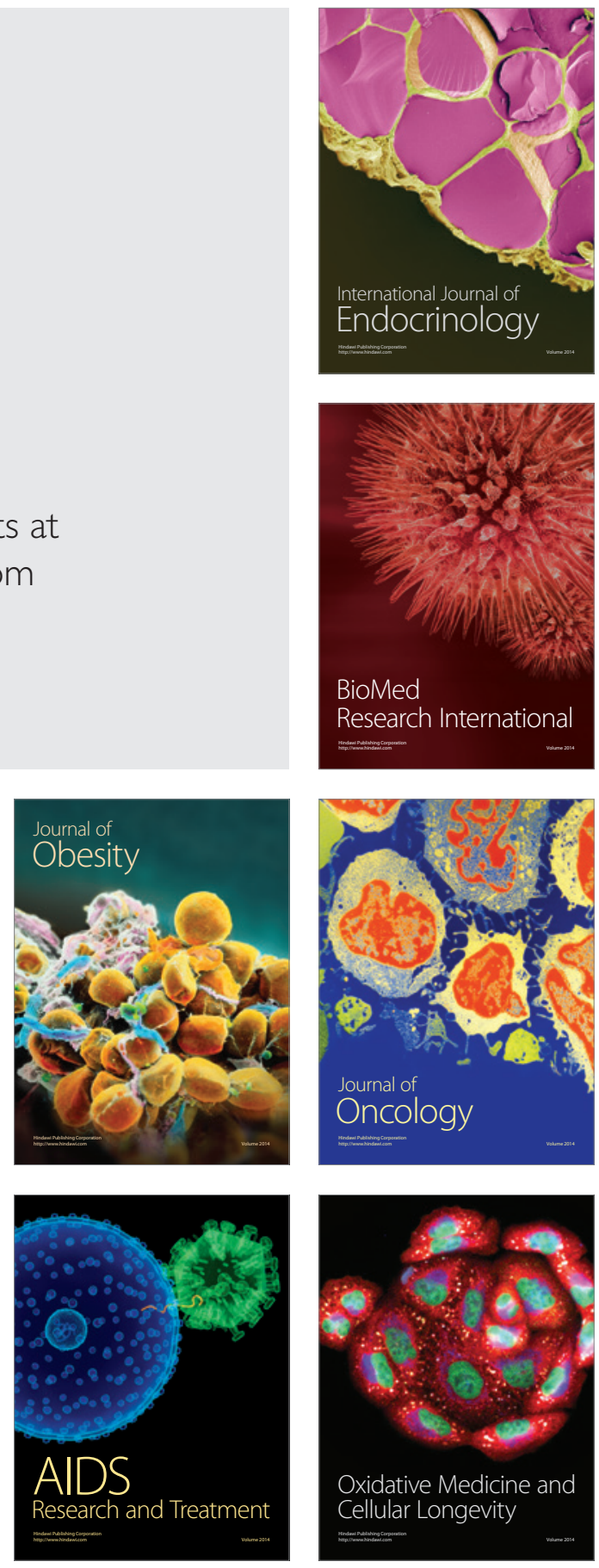